\title{
Rusaddir: de la memoria literaria a la realidad histórica de la expansión fenicio-púnica en Occidente
}

\author{
Russadir: from the Literally Memory to the Historical Reality of \\ the Phoenician-Punic Expansion in West
}

\begin{abstract}
Fernando López PARDO
Publicado por primera vez en Melilla y su entorno en la Antigüedad (=Aldaba 30), 1998, Melilla, 35-52
\end{abstract}

En 1945, Rafael Fernández de Castro, ilustre cronista de la ciudad, señalaba que Rusaddir fue fundada allá por los siglos XI ó X a.C. en el contexto de las más antiguas factorías fenicias en la costa septentrional africana, poco después del establecimiento de los fenicios en las islas de Gadeira. ${ }^{1}$ Aunque reconoce la inexistencia de pruebas, aduce que fue una fundación "inevitable". "La privilegiada situación del 'Promuntorium Rusadir' (península de Tres Forcas) sobre la costa mediterránea del actual Marruecos, no pudo pasar inadvertida para aquellos primeros navegantes en sus frecuentes viajes hacia las Columnas de Hércules. Al bordear su costa, es forzoso advirtiesen la conveniencia de fundar allí, en la parte oriental y quizá tal vez en la occidental (Cazaza?) uno de los 'bancos' o factorías comerciales de que se dice sembraron el litoral...."2

Para otros, más recientemente, Rusaddir fue una de las colonias comerciales fenicias fundadas por Tiro a partir del siglo VIII a.C. Ese descenso cronológico no se debe a que hayan aparecido pruebas que permitan establecer la nueva datación para la localidad, sino al afianzamiento de la tesis de que la expansión fenicia en Occidente no comenzó hasta el siglo VIII a.C., de tal manera que si se quería contextualizar este establecimiento norteafricano en ese proceso era obligado atribuirle esa nueva datación. Se trata en ambos casos de hacer remontar la fundación de la ciudad a los orígenes de la expansión fenicia en Occidente, basándose más en un acto de voluntarismo que en la existencia de indicios veraces. La posición hipercrítica adoptada por otros investigadores parece alejarse aún más de la realidad histórica, al considerar el enclave magrebí una fundación púnica tardía, contabilizando sólo los restos arqueológicos hallados en su suelo. Una buena muestra de ello es que en ningún trabajo científico sobre la expansión fenicia en Occidente, aparece incluida Rusaddir, sólo se habla del enclave cuando se trata del final de la época púnica, quizás en un exceso de incredulidad, incorporando al discurso histórico sólo la escasa y tardía documen-

1 Fernández de Castro y Pedrera 1945, 125-129.

2 Fernández de Castro y Pedrera 1945, 128. 
tación arqueológica. Así pues, como podemos apreciar, hoy en día se encuentra en discusión el problema de los orígenes de la localidad en un marco cronológico extraordinariamente amplio a la vez que muy inseguro, aunque es fácil colegir que la última propuesta tiene pocos visos de verosimilitud.

En una época como la nuestra los trabajos arqueológicos suelen precisar el nacimiento de muchas localidades, a veces más allá de lo que nos dicen las fuentes literarias, aunque en algunos casos, es verdad, desmienten pasados míticos. Por lo que se refiere a Melilla nos encontramos sin embargo con una situación inversa por ahora, las fuentes literarias, dentro de una imprecisión cronológica remarcable, señalan que esta tuvo un pasado más amplio de lo que ponen de manifiesto los pocos restos arqueológicos que ha deparado su suelo.

Las noticias que se refieren a esta localidad en la Antigüedad no se inscriben dentro de la que conocemos como literatura histórica, aquella que en época clásica se preocupaba de poner a salvo los hechos, creando con la sucesión temporal de ellos la noción de pasado histórico, de igual manera que la épica se encargaba de conservar el recuerdo de la "gloria" inmortal de los héroes. ${ }^{3}$ Las referencias más arcaicas proceden de periplos y descripciones cartográficas que habitualmente no cuentan con una noción de sucesión temporal. ${ }^{4}$ Pero sin embargo, a pesar de carecer de esa noción de carácter cronológico, estas afirmaciones se tornan más valiosas para el historiador en el instante en que se pueden inscribir en un marco temporal preciso. Los esfuerzos de filólogos e historiadores por datar documentos antiguos no son banales, pues concretar la datación de las informaciones recogidas en documentos antiguos es condición necesaria para un uso preciso de las mismas en la reconstrucción histórica.

\section{La ciudad de Akros en el periplo del Pseudo-Scylax}

En esta prolija pero confusa obra, el Periplo del Pseudo-Scylax, se cita una ciudad con el nombre de Akros, que cuenta con un puerto y tiene en sus proximidades un

\footnotetext{
3 CANFora 1972.

4 Hoy en día está plenamente aceptado que el nombre antiguo de Melilla fue Rusaddir, pues contamos con el apoyo de numerosas fuentes antiguas bien contrastadas. Quizás el documento más preciso sea el Itinerario de Antonino, dado el número de referencias geográficas que ofrece y las distancias reseñadas. En este texto no hay duda de que el cabo Russadir es el de Tres Forcas o Rus-er-Dir y Melilla, Russsadir Colonia. Plinio también cita el oppidum de Rhyssadir en los mismos parajes, entre el uadi Laud y el Malvane (Plin. Nat. Hist. V, 18). Y la Geografía de Ptolomeo entre el cabo Sestiaria y el Metagonitis. Tampoco hay dudas acerca de la atribución del nombre al gran promontorio, que ha conservado hasta este siglo el nombre arabizado de Mus-er-Dir (Fernández de CASTRo y Pedrera 1945, 44). La existencia de otra Rhysaddir, esta vez un puerto en la costa atlántica africana identificado en el periplo de Polibio recogido por Plinio (Nat. Hist. V, 9), nos viene a confirmar la idea de que en la literatura periplea importantes accidentes geográficos transfieren sus denominaciones a localidades u otros elementos geográficos próximos. Contamos pues con un ejemplo totalmente ad hoc para el caso que nos ocupa. En una sucesión de ríos, cabos, golfos, puertos y entidades étnicas aparece mencionado el puerto de Rhysaddir, que en el relato se encuentra después de otro puerto, el de Rutubis y del promunturium Solis, siendo admitido generalmente que se encontraría junto al cabo Ghir (ROGET 1924, 66-67; Desanges 1978, 135). No en vano Ptolomeo sitúa su cabo Risódeiron (Ptol. IV, 2 y IV, 6) por estas latitudes lo cual hace sospechar fundadamente que el puerto, seguramente natural, recibe tal nombre por encontrarse junto al promontorio, calificado así en lengua fenicio-púnica por su aspecto imponente.
} 
golfo. ${ }^{5}$ Se encuentra entre dos hitos geográficos reconocibles aunque algo distantes, por un lado Abila, la Columna de Heracles en África, y por el otro la ciudad de Siga, la actual Takembrit, en el río del mismo nombre, conocido ahora como uadi Tafna y delante una isla, fácilmente identificable con la isla del faro de Rachgoun. Todo ello induce a identificar Akros con Rusaddir, tanto por los indicios topográficos, pues la amplísima albufera conocida como Mar Chica (Sebja bu Arg) sería el golfo señalado y muy probablemente el gran cabo es reconocible en el promontorio de Tres Forcas (Rus er Dir), como por el hecho de que el nombre de Akros parece traducir parte del topónimo púnico Rusaddir.

La lectura del texto sigue siendo problemática. En la edición más conocida del mismo, K. Müller llama Akra a la isla que se encuentra delante de Siga, considerando poco probable que el apelativo "gran ciudad" que viene a continuación se refiera a una innominada localidad dentro de la isla, dadas sus escasas dimensiones, considerando pues que tal calificativo se refiere a la localidad de Akros (Rusaddir?) que menciona después. ${ }^{6}$ Aunque la idea es muy sugerente y quisiéramos ver en Rusaddir un gran centro urbano, la reconstrucción es enormemente forzada, sobre todo por el hecho de que en todo el amplio párrafo que señala accidentes y localidades desde Cartago hasta las Columnas, no se destaca ninguna ciudad con apelativo alguno, solamente señala la existencia de unas "pequeñas" islas habitadas por los cartagineses, Gaulos (Gozzo) y Melitè (Malta). No dejaría de ser enormemente extraño que si no dice de Cartago o de Utica que son "grandes", como va a atribuir ese calificativo a Akros. Roget ofrece una lectura del texto mucho más acorde con la realidad geográfica y arqueológica de la región, lo cual le obliga a trastrocar Akra polis megale (Akros, gran ciudad) por Akra megale polis (ciudad del Gran Cabo), lo cual obliga a no atribuir el nombre a la isla de Rachgoun y reconocer por el contrario la existencia de un "gran cabo".

En cualquiera de los casos y a pesar de que la lectura de Roget nos parece la más adecuada, nuestro discurso no queda alterado sea cual sea la interpretación correcta, pues lo que se trata aquí son las cuestiones de tipo cronológico que se derivan del hecho constatado de que Akros es Rusaddir en la obra del Pseudo-Scylax, sea esta la ciudad del Gran Cabo o bien una gran urbe.

Aunque existe acuerdo de que la obra fue estructurada antes de las transformaciones debidas a Alejandro Magno, fechándose por lo tanto su redacción en la segunda mitad del siglo IV a.C., la documentación de algunas partes de ella pueden ser anteriores, datables de los siglos VI y V a.C. ${ }^{7}$ Sin embargo, precisamente el párrafo que nos ocupa no aporta indicios de estratificación ni de añadidos, sino que presenta una gran homogeneidad, al menos aparente. Tampoco, al igual que el resto del periplo, incluye elementos conocidos en obras consideradas de tradición arcaica, como el periplo de Hannon o los fragmentos que nos han llegado de Hecateo de Mileto. ${ }^{8}$ Así pues, haciendo un ejercicio de prudencia hemos de reconocer que la referencia del Pseudo-Scylax a Akros permite remontar la existencia de Rusaddir a mediados del

5 MÜLLER 1965, 107-112.

6 MÜLler 1965, 90.

7 Peretti 1961; Desanges 1978, 92-94; Domínguez Monedero 1994, 63.

8 Desanges 1978, 94. 
siglo IV a.C. como datación más baja. Se trata de un dato de no poca relevancia, pues cuando menos supera en más de un siglo la datación de los restos arqueológicos hasta ahora reseñados.

\section{Metagonion, la ciudad del "promontorio esquinado"}

No conocemos ninguna referencia más antigua en las fuentes literarias que de forma más o menos explícita trate de Rusaddir, pero no se excluye que la localidad pudiera ser conocida también con otro nombre. Nada impide que en algunos portulanos y periplos se hayan conservado denominaciones diferentes, en función de otras tradiciones marineras. Sabemos que algunas de estas tradiciones están más atentas a las denominaciones usadas en la región, intentando reproducir fonéticamente el nombre local (este parece ser el caso del uso del término Rusaddir en los textos griegos y latinos), otras, traducen su significado, como parece hacerlo parcialmente el Pseudo-Scylax al nombrar la localidad de Akros junto al gran promontorio, $\mathrm{y}$ en fin, en otras ocasiones los marinos recuerdan ensenadas, golfos, islas, promontorios, etc. por nombres que de alguna manera los describen. Ejemplos no faltan en la literatura periplea ${ }^{9}$ y este es el camino que queremos emprender para proponer una posible duplicidad en la denominación de este enclave y del gran cabo próximo, quizás también conocidos como Metagonion entre los griegos.

Según recoge Esteban de Bizancio, Hecateo de Mileto señaló la existencia de una ciudad en Libya llamada Metagonion..$^{10}$ Este topónimo sirvió para identificar también un promontorio, una región desértica y un pueblo al decir de Estrabón, el cual nos da las referencias más precisas para su localización. ${ }^{11}$ El promontorio y la región árida se situarían cerca del río Molochath (Muluya). Aunque se ha querido identificar el promontorio Metagonion con el cabo del Agua, situado a oriente de Rusaddir. más cerca del gran río que separa la Mauritania Occidental del territorio de los Masaesylios, se trata sin duda del cabo Tres Forcas o Rus-er-Dir. El equívoco procede ya de Ptolomeo ${ }^{12}$ que da el nombre de Sestiaria Akra al Cabo Tres Forcas y señala a continuación de Rusadir el cabo Metagonitis, pero si seguimos a Estrabón,,$^{13}$ que dice que el promontorio se encuentra frente a Carthago Nova, por fuerza se tiene que tratar de un accidente especialmente relevante como el cabo Tres Forcas y no el cabo del Agua o Ras Sidi Bechir, poco visible para los marinos. La importancia del promontorio viene señalada en el propio texto de Estrabón al destacar este que Timósthenes se equivoca situándolo a la altura de Massalia, sin duda porque aplica el mismo nombre al cabo Treton, otro jalón geográfico de indudable importancia. ${ }^{14}$ Quizás la prueba más concluyente esté contenida en el significado del topónimo, que parece provenir de la expresión griega metà to gónion akron que designa un país situado más allá de un cabo especialmente anguloso o pronunciado. ${ }^{15}$ También precisa-

9 T.H.A. I, 1994, passim.

10 St. Byz. Frag. 324, Müller 1965, 24.

11 Str. XVII, 3, 6.

12 Ptol. IV, 3.

13 Str. XVII, 3, 6.

14 Desanges 1980, 188.

15 R.E. s.v. "Metagonion”, 1320-21; con mayor precisión, Desanges 1980, 188. 
mente se aplica el nombre artificioso de metagonitas al pueblo que habita entre este cabo y las Columnas de Heracles, ${ }^{16}$ pues visto desde el Mediterráneo Central, naturalmente este pueblo "se encuentra más allá del cabo pronunciado". ${ }^{17}$

En suma, caben enormes posibilidades de que la ciudad llamada por los griegos con el mismo nombre que el promontorio Metagonion, igual que para los fenicios occidentales recibía el nombre también del promontorio Rusaddir, sean una misma. El interés de este hecho no reside sólo en descubrir otra denominación y en sumar las informaciones de las fuentes antiguas asociadas a este topónimo a las de Rusaddir, sino que contiene implicaciones sobre los orígenes de la localidad y de la expansión fenicia en la costa norteafricana.

Como decíamos al principio, las referencias literarias se convierten en referencias históricas ciertas en tanto que cronológicas en el momento en que podemos datar la época en que vivió el autor que las escribió. En esta ocasión tendría poco valor si los autores que nos hablan de Metagonion fueran sólo Estrabón o Ptolomeo, ya que estos son claramente posteriores a la redacción del Periplo del Pseudo-Scylax, que como vemos es hasta ahora la referencia ante quem más arcaica. Pero al entrar Hecateo de Mileto en el grupo de autores que citan el topónimo Metagonion, debemos considerar que la localidad homónima es al menos contemporánea del autor griego, el cual escribió durante la segunda mitad del siglo VI a.C. ${ }^{18}$ En suma, no parece descabellado proponer que Rusaddir era un enclave fenicio ya consolidado en el siglo VI a.C. y es posible incluso que tuviera mayor antigüedad.

\section{Rusaddir y "la civilización de los promontorios rocosos"}

Con estas nuevas premisas cronológicas, la apreciación sobre el enclave norteafricano cambia forzosamente, especialmente en lo que se refiere a las características del hábitat y a las funciones que pudo desempeñar en el contexto regional. Por otro lado viene a colmar un vacío de conocimiento notable a la vez que molesto. La investigación arqueológica en la costa rifeña no había sido capaz de sacar a la luz ningún asentamiento fenicio entre el cabo Espartel, en la fachada atlántica del Estrecho, y el Oranesado, ${ }^{19}$ poniendo de manifiesto una vez más el carácter fragmentario de la búsqueda arqueológica.

No obstante últimamente empiezan a aflorar indicios de presencia fenicia en esta línea de costa, la cual es posible asociar claramente con una relación comercial continuada con las poblaciones autóctonas a partir de los siglos VII y VI a.C. al menos.

16 Str. III, 5,5; Ptol. IV, 1, 5.

17 Hecateo cita también una ciudad de los libios llamada Melissa, que ha sido relacionada con Melilla, una fundación hannoniana, y que algunos han querido identificar también con Rusaddir, tanto por el parecido con el nombre actual como por la abeja que aparece en sus acuñaciones monetales, CARCOPINO 1940, 103; Jodin 1976. Las posibilidades de que sea así no dejan de ser remotas, de la misma manera que los indicios siguen siendo débiles. En este respecto el argumento principal utilizado sigue siendo poco consistente, la abeja representada en el anverso de las monedas rusaddirenses se puede relacionar con la diosa Astarté más que con una destacada producción de miel de la localidad.

18 T.H.A. I, 1994, 23 y 38-39.

19 Tarradell Mateu 1958, 74; ID. 1966, 425; Sierra del Molino 1988, 475-476. 
Cabe señalar el caso de Tingi que se encuentra con una problemática similar a la de Rusaddir. El importante núcleo tingitano no ha deparado recientemente ningún hallazgo arqueológico que nos permita replantearnos su origen, los vestigios más antiguos hasta ahora encontrados bajo la ciudad actual siguen siendo de finales del siglo V a.C. ${ }^{20}$ Ahora bien, sabemos que Hecateo de Mileto en su lista de ciudades norteafricanas incluye la ciudad de Thingé en Libya ${ }^{21}$ noticia que hay que situar sin duda en el siglo VI a.C. Es necesario pues valorar de nuevo el importante papel que pudo jugar Tingi como centro fenicio en relación con las poblaciones autóctonas de la región tangerina puesto de manifiesto a través de sus necrópolis diseminadas por el territorio.

Un caso similar es el de Sidi Abdselam del Behar. El hábitat se encuentra en la desembocadura del Uadi Martil, en un estuario fósil del río, sobre una pequeña colina donde se localiza el "morabito" que da nombre al lugar. En dicha colina M. Tarradell ${ }^{22}$ realizó un sondeo en el que aparecieron vestigios de un pequeño asentamiento, que él fechó en el siglo $V$ a.C. Hoy en día es posible sin embargo retrotraer el enclave hasta los siglos VII-VI a.C. a juzgar por los materiales recuperados en esas excavaciones. El nivel más antiguo cuenta ya con restos constructivos y con materiales cerámicos variados, es abundante la cerámica hecha a mano de paredes gruesas sin decoración y la cerámica a torno, con fragmentos de platos y cuencos de engobe rojo, ánforas R 1 fenicias y cerámicas pintadas con líneas y bandas. En cuanto a su función parece que se trata de una pequeña factoría relacionada con la extracción de recursos del amplio valle del Martil ${ }^{23}$ y de las cuencas cercanas, como están poniendo de manifiesto los cada vez más cuantiosos hallazgos coloniales en los asentamientos autóctonos de la región.

Uno de los más sorprendentes es una fíbula tipo Acebuchal de Tamuda ${ }^{24}$ no por el objeto en sí, sino porque de ser fiable la localización haría remontar el asentamiento nada menos que hasta los siglos VII-VI a.C., cuando hasta ahora la fecha propuesta para su origen no rebasaba el s. III a.C. Por otro lado, en la cueva de Caf Taht el Gar, situada en una zona abrupta próxima al valle del Martil, se encontraron sobre un estrato de Bronce II cerámicas a torno, que inmediatamente M. Tarradell ${ }^{25}$ consideró idénticas a las halladas en Cudia Tebmain y Sidi Abdselam. También apareció una arracada de oro de tipo púnico datada por A. Jodin ${ }^{26}$ en torno al s. V a.C. El uadi Lau, es otro cauce con un valle de considerable amplitud, a unos $30 \mathrm{~km}$ de la desembocadura del Martil. Allí, el yacimiento de Kach Kouch, sito a 9 km de la desembocadura, ha provisto materiales cerámicos fenicios en un contexto de cerámicas hechas a mano. La datación propuesta lato sensu por los excavadores para estos materiales va del s. VIII al VI a.C. ${ }^{27}$

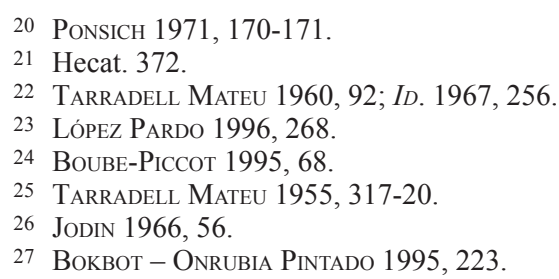


Aunque los hallazgos de Kach Kouch se pueden poner en relación con la factoría de Sidi Abdeselam, su alejamiento de la desembocadura del Martil y la amplitud del valle del Lau, sugieren la necesidad de buscar un enclave fenicio, aunque fuera meramente estacional, en sus proximidades. Vemos pues como un mínimo esfuerzo de investigación está poniendo de manifiesto que la presencia fenicia en esta línea de costa alcanzó tal dimensión que se puede hablar de un control efectivo de la misma por parte de estos colonizadores. El vacío hasta ahora señalado en el resto de la costa del Rif parece ser fruto de las dificultades para trabajar en un territorio con intrincados accesos y a la falta de proyectos recientes dedicados al análisis de la dinámica de la ocupación humana durante la Antigüedad en los valles de mayor interés de la franja rifeña, entre los que parece especialmente perentorio el estudio del valle del Martil.

El estudio descontextualizado de las factorías fenicias sin un análisis riguroso de los yacimientos del territorio en el que fueron instaladas ha llevado en múltiples casos a un desconocimiento casi absoluto del alcance y características de las relaciones de estos asentamientos con el territorio circundante. Esta situación ha influido sensiblemente en las investigaciones arqueológicas sobre la colonización fenicia en la Península Ibérica, de tal suerte que aún nos encontramos enzarzados en un vaivén de modelos teóricos que pretenden explicar la causa de las distintas fundaciones y sobre qué base económica apoyaban su supervivencia, cuando las interrogantes planteadas podrían tener respuesta a través de proyectos de investigación interdisciplinares de carácter territorial. El problema tiene un alcance inusitado, pues no se trata simplemente de un desconocimiento de la interacción fenicios-población autóctona en un territorio dado, sino que llega a tocar de lleno la problemática general de la expansión fenicia en el Extremo Occidente, pues aún nos estamos cuestionando, sin obtener una respuesta clara, las características básicas de la misma. El impresionante volumen de restos arqueológicos recuperados hasta ahora no se corresponde de ninguna manera con el conocimiento real de la dinámica histórica, pues estos adolecen de una clara contextualización macroespacial que permita relacionar los restos muebles con el uso del espacio por parte de los que los utilizan, para poder inferir de ello cómo se produjo la relación de los hombres con el medio, y naturalmente de qué carácter fueron los lazos que mantuvieron los colonos con la población indígena, las cuales son imposibles de discriminar a través de una secuencia vertical.

El estado de la investigación sobre el Magreb es aún más precario. Al escaso volumen de restos arqueológicos recuperados, se suman la antigüedad de su publicación y su explicación a través de modelos teóricos ya ampliamente superados. Cuando se ha pretendido incorporar la documentación africana a un nuevo discurso, por lo general esta ha sido manipulada incorrectamente, normalmente con el fin de sumar nuevas pruebas para apoyar propuestas enormemente endebles y hoy poco apreciadas, con lo cual, las explicaciones que aún permanecen son las que fueron propuestas en el momento en que se recuperaron los vestigios.

De esta manera, tanto Sidi Abdselam del Behar como Cudia Tebmain sobre el uadi Emsá y Rusaddir siguen siendo interpretados como escalas púnicas para la navegación de regreso desde los asentamientos del Estrecho a Cartago, siguiendo el modelo 
propuesto por Pierre Cintas. ${ }^{28}$ Según el gran arqueólogo de Cartago, los barcos púnicos necesitaban hacer escalas nocturnas y por lo tanto el litoral debía de estar jalonado de estaciones regularmente distribuidas con una distancia entre ellas de menos de treinta kilómetros. De esta manera, un número importante de yacimientos fenicios, que empezaban a descubrirse y a los que no era posible atribuir fácilmente una relación comercial destacada con los indígenas del entorno, dejaron de ser considerados factorías mercantiles y pasaron a ser imaginados como escalas náuticas.

Los enclaves rífeños analizados por Miguel Tarradell formarían parte de una estructura naval más amplia que abarcaba también el Oranesado, donde G. Vuillemot ${ }^{29}$ atribuyó las mismas funciones a los asentamientos fenicios y de época púnica que fue sacando a la luz, pero poniendo de manifiesto la falta de regularidad en las distancias entre las supuestas escalas. Al hilo de esta propuesta de los asentamientos oraneses, Rusaddir, dadas las características de su entorno fue fácilmente evocada como una más de estas supuestas escalas navales, pero de época tardía.

Creemos que con respecto a la costa norteafricana no se puede seguir identificando como escalas todos los enclaves fenicios, es necesario replantearse las características de la colonización fenicia en este ámbito desde una nueva perspectiva. El análisis del conjunto de asentamientos oraneses contribuye a sostener la idea que hemos propuesto para Tingi y Sidi Abdselam del Behar. Formando unos y otros parte de la misma área económica y cultural que los asentamientos sitos en la Península Ibérica.

El islote de Rachgoun, aunque alejado de la costa, se encuentra frente a la desembocadura del río Tafna, cauce de agua permanente y en parte navegable. A cinco km de su desembocadura se localizan las ruinas de Siga, la que llegó a ser capital del rey Syphax, cuya existencia se documenta al menos desde el siglo IV a.C. también a través de la obra del Pseudo-Scylax, lo cual nos sirve para ilustrar el interés económico de la zona. Por otro lado, parece ser que junto a la margen derecha del río, en el promontorio de la Tour maure, se han localizado cerámicas fenicias, lo cual ha permitido suponer a G. Vuillemot, ${ }^{30}$ creo que con acierto, que es el embarcadero de tierra firme de los fenicios del islote. Por todo ello, no parecería descabellado suponer que Rachgoun fuera realmente una factoría comercial que drenara los recursos del valle del Tafna. La forma de cubrir las necesidades alimenticias consistió sin duda en la pesca y en menor medida a través de la adquisición de alimentos a los indígenas. La abundante pesca estacional, y sobre todo la posibilidad de su larga conservación quizás sean la clave de la supervivencia de muchos de los enclaves fenicios costeros a los cuales se les ha supuesto que cubrían su abastecimiento alimenticio por otros medios. ${ }^{31}$

Por su parte el enclave de Mersa Madakh parece una pequeña factoría pesquera ocupada por lo menos a lo largo del s. VI a.C. y que se inserta en el pujante desarrollo de la producción de los derivados de la pesca que empieza a documentarse muy bien en otros lugares, como Kuass en el mismo siglo, Emsá, Las Redes, etc., más tarde. ${ }^{32}$

\footnotetext{
28 Cintas 1948.

29 Vuillemot 1965, 47.

30 Vuillemot 1965, 35.

31 López Pardo 1996, 270-272.

32 López PARdo 1996, 272-274.
} 
En resumen y haciendo un análisis global, creemos que Rusaddir se inscribe en un proceso colonizador que cuenta con tres períodos claramente diferenciados. Hoy por hoy, y mientras descubrimientos futuros no demuestren lo contrario, parece difícil su inserción en la fase inicial de la expansión fenicia, la cual se caracteriza por la implantación en el Extremo Occidente hasta mediados del siglo VIII a.C. de unos escasos pero grandes núcleos de habitación con clara vocación mercantil. En Marruecos es Lixus la que obviamente desempeña el papel de gestor de casi toda la actividad comercial en la zona atlántica africana durante el s. VIII y primera mitad del VII a.C.

Rusaddir parece desarrollarse en la segunda etapa norteafricana de la colonización, a juzgar por los datos de procedencia literaria y el contexto arqueológico de los demás asentamientos de la región. Este período se caracteriza en el caso norteafricano por una implantación colonial amplia pero que no pretende una sustancial ocupación de la costa, sino instalar factorías en aquellos lugares que permiten un acceso directo y rápido a concentraciones indígenas importantes localizadas habitualmente en los grandes valles fluviales que pueden proveer materias primas de interés para los fenicios. Véase si no los valles de La Tafna, Lau, Martil, Loukkos y Sebú además de Mogador (Essaouira), el puerto del valle del Sous. La elección de este patrón básico explicaría la ausencia de factorías fenicias en amplios frentes costeros de Argelia y Marruecos, en especial El Rif, donde muchos cauces fluviales son cortos y proceden de orografias muy quebradas y próximas a la costa y por lo tanto son zonas muy escasamente pobladas, de insuficiente interés para situar enclaves fenicios permanentes. ${ }^{33}$

Dicho proceso parece documentarse desde mediados del siglo VII a.C. con el establecimiento de enclaves comerciales, como Mogador, Sidi Abdselam y Rachgoun, todos ellos con una cultura material tipológicamente muy homogénea y que parecen formar parte de la misma colonización secundaria procedente de los asentamientos fenicios más antiguos de la región. ${ }^{34}$

Por otro lado se puede descartar una hipotética sucesión regular de escalas para la navegación tanto en las costas argelinas como en las marroquíes. Aunque no debemos desdeñar la conveniencia de que los enclaves diseminados de forma irregular por la costa atlántica y la mediterránea, ocupados en otros menesteres, sirvieran además de refugio a los barcos mercantes fenicios.

La tercera fase se iniciaría a partir del siglo VI a. C, cuando se constata la fundación de poblados especializados en la pesca y en la elaboración de salazones de pescado, como Kuass y Mersa Madakh, y más tarde Kudia Tebmain, y quizás Ksar Seguir y en

33 López PARdo 1996, 275-276.

34 La colonización secundaria no debe entenderse como un proceso diferente a la colonización primaria en razón de la procedencia, la más antigua a partir de Tiro y la más moderna a partir de las colonias consolidadas, pues las evidencias vienen a mostrar que la cultura material de los niveles de fundación de los asentamientos organizados en la segunda mitad del s. VIII a.C., no pertenecientes por lo tanto a lo que llamamos colonización secundaria, es una cultura reelaborada ya en el Extremo Occidente, con lo cual difícilmente se puede hablar de una implantación colonial organizada directamente desde Tiro. El cambio sustancial entre una y otra reside en la incorporación en esta última de un considerable número de individuos indígenas integrados en buena parle en la estructura socioeconómica de las colonias matrices y que son utilizados como mano de obra en este nuevo proceso de expansión, dicha incorporación se detecta claramente en los vestigios de las nuevas fundaciones. 
la bahía de Benzú. La proliferación de tal tipo de asentamiento no indica el nacimiento de esta actividad económica en esa época, sino que es el reflejo de su intensificación y por lo tanto la necesidad de desarrollarla en factorías propiamente pesqueras.

Si bien este es el contexto histórico regional en el que se inserta Rusaddir, no es fácil asignarle, sin riesgo a equivocarse con certeza, el papel que pudo desempeñar en el mismo. En este sentido, no parece equiparable ni a Sidi Abdselam del Behar ni a Rachgoun pues estos asentamientos se encuentran en la desembocadura de dos grande ríos, Rusaddir por el contrario cuenta sólo con un pequeño uadi en sus inmediaciones, aunque no a excesiva distancia del río Muluya, amplísima cuenca fluvial que hunde sus raíces en las estribaciones del Atlas. Precisamente por ello parece evidente su parecido con Mogador (Essaouira), que aunque ubicado frente al estuario de un pequeño río, es considerado el puerto del amplio valle del Sous. Sin embargo, poca información hay de las posibilidades comerciales de la cuenca del Muluya, aunque de forma indirecta sabemos de su potencial en marfil, huevos de avestruz, pieles y cuernos de gacela, a través de los grabados rupestres de Aït bou Ichaouen en la vertiente opuesta de la cuenca del Muluya en el Alto Atlas..$^{35}$ Tales recursos podían ir a parar a Rusaddir como el enclave fenicio costero más próximo.

Los indicios referidos a esa época no nos permiten ir más lejos. Los datos de épocas posteriores parecen destacar el carácter portuario del enclave (Rhysaddir oppidum et portus), ${ }^{36}$ con la posibilidad de controlar visualmente toda la costa oriental de la península de Tres Forcas desde el peñasco. ${ }^{37}$ Parece pues innegable, que aunque el enclave desarrollara otras actividades ${ }^{38}$ llegó a desempeñar una función de escala náutica ante la necesidad de relacionar el Mediterráneo Oriental y las factorías de la región de Orán con sus colonias matrices de la región del Estrecho, tanto para los barcos que iban costeando junto a las tierras africanas, así como para aquellos que seguían el derrotero de la costa andaluza para alcanzar después las costas africanas camino de Cartago.

\section{En la esfera de Cartago}

El Pseudo-Scilax después de describirnos la costa de Libya y antes de referir lo que hay más allá de las Columnas de Heracles cierra el texto afirmando que todas las ciudades y factorías indicadas desde La Syrte hasta el Estrecho pertenecen a los cartagineses. ${ }^{39}$

Aunque siempre es posible sospechar que esta referencia puede ser un añadido posterior, no correspondiente al cuerpo original del texto, existen indicios que nos

35 Greisson 1973-1975.

36 Plin. Nat. Hist. V, 18, 5.

37 Fernandez de Castro y Pedrera 1945, 129.

38 Las posibilidades pesqueras de sus aguas parecen innegables. La Mar Chica (Sebjá bu Arg o El Bahar Seguer), seguramente el gran golfo citado por el Pseudo-Scylax, ha sido hasta hace poco una amplia albufera de $25 \mathrm{krn}$ de largo comunicada por una bocana con el mar, la cual ha sido una auténtica reserva pesquera para las poblaciones del entorno durante siglos. Muy abrigada del oleaje permitía la pesca durante, todo el año (Fernández de CAstro y Pedrera 1945, 70). Por otro lado era conocida por los antiguos la aridez del territorio circundante (Str. XVII. 3, 6).

39 MÜller 1965, 111. 
hacen suponer que forma parte del mismo. A diferencia de otros párrafos, como el que le sigue ${ }^{40}$ donde se aprecia claramente la existencia de inserciones de carácter etnográfico, comercial, etc., el párrafo que nos ocupa presenta una homogeneidad extraordinaria, centrado sólo en tres cuestiones, sucesión de ríos, cabos, islas, puertos y localidades, por otro lado, días de navegación entre los extremos, y por último dos referencias a los dueños de las localidades. La primera de estas referencias señala que los habitantes de las pequeñas islas, entre las que están Gozzo y Malta, son cartagineses y la segunda es la que habíamos señalado hace un momento, que toda la costa desde La Syrte a las Columnas es también de Cartago. Este tipo de información era de especial interés para los nautas griegos, a quienes va dirigida esta obra, se les está señalando, que a diferencia de la costa entre Cartago y Egipto, donde hay asentamientos griegos, en esta no hay ninguno.

La información se puede poner en relación con la prohibición para Roma y sus aliados de navegar y de recalar en puertos de la costa norteafricana desde el Kalos Akroterion (Túnez) hasta Mastia (Región de Cartagena) que aparece reflejado en el segundo tratado romano-cartaginés, de mediados del s. IV a.C. ${ }^{41}$ Ya estamos lejos del tiempo en que la libertad de navegación y comercio en aguas del Mediterráneo era una realidad, de tal manera que este tipo de información se convirtió en totalmente necesaria para los barcos mercantes.

Todo parece indicar pues que desde la segunda mitad del s. IV a.C. al menos, quizás incluso antes, a pesar de que no podemos precisar si esta parte pudo remontar al siglo V o incluso a la segunda mitad del VI a.C., Rusaddir se encuentra en la esfera de influencia de Cartago y que ha adquirido una especial relevancia estratégica para la metrópoli púnica en su cada vez más importante presencia en el Extremo Occidente. A este respecto es especialmente significativo que desde Siga hasta las Columnas, Akros es la única localidad mencionada, de tal manera que es fácil sospechar su importancia para la navegación, no olvidemos que se encuentra inserta en la descripción de una obra para navegantes.

El paso a la esfera de influencia de Cartago tuvo importantes consecuencias para la ciudad. Creo que existen indicios de que Rusaddir recibió elementos libiofenicios en un contexto colonizador muy amplio señalado por otras fuentes, como Herodoto o el Periplo de Hannon, que pareció englobar la costa sur de la Península Ibérica y el Marruecos atlántico. Los peculiares enterramientos de los siglos II y I a.C. del Cerro de San Lorenzo con inhumaciones en fosas cubiertas por varias ánforas, normalmente en número impar, de 3 hasta un máximo de 9 y colocadas de forma contrapuesta sobre la fosa ${ }^{42}$ son especialmente similares a las de la necrópolis de Olbia, en Cerdeña, ${ }^{43}$ isla que había pasado bajo dominación de Cartago tiempo atrás.

Por otro lado, existe un rastro numismático de esta relación de dependencia con la metrópoli centromediterránea. Se trata del hallazgo de un numerosísimo conjunto

40 MÜLLER 1965, 112.

41 Pol. III, 24; SCARDigLi 1991, 105-108.

42 Fernández de Castro y Pedrera 1950. Los materiales se fechan en su mayoría en el s. I a.C. Véase TaRradell Mateu 1954, 261; Ramón 1995, 99-100.

43 Acquaro 1983, 49. 
de monedas procedente del dragado del puerto, hallazgo muy valioso para conocer la circulación monetaria y en definitiva las relaciones comerciales que se desarrollaban vía Rusaddir en el siglo III a.C.

En definitiva y para concluir creemos que Rusaddir no es una fundación de Cartago, sino que su origen debemos atribuírselo en última instancia a Tiro, la gestora y beneficiaria última del esfuerzo colonizador fenicio en el Extremo Occidente. Esfuerzo que es gestionado y articulado desde los asentamientos occidentales preexistentes que contaban con un conocimiento preciso del terreno así como de las necesidades de infraestructura que se iban generando para una extracción de recursos cada vez más perfeccionada y contando con una creciente disponibilidad de medios humanos y económicos.

\section{Bibliografía}

Acquaro, E. (1983): "L’Espansione fenicia in África", [en] Convegno sul tema: Fenici e Arabi nel Mediterráneo, Roma, 23-61.

BARRIO, C. (1983): "Bereberes y fenicios en Melilla: aportaciones de la numismática", [en] Aproximaciones a las culturas mediterráneas del Norte de África (I), Melilla, 65-80.

Bоквот, Y. - OnRUBia-Pintado, J. (1995): "Substrat autochtone et colonisation phénicienne au Maroc. Nouvelles recherches protohistoriques dans la péninsule tingitane", [en] P. Trousset (éd.), L'Afrique du Nord antique et médiévale. Productions et exportations africaines. Actualités archéologiques (VIe Colloque international sur l'histoire et l'archéologie de l'Afrique du Nord, Pau, 1993), Paris, 1995, 219-229.

Boube-Piccoт, Сн. (1995): "Bronzes antiques. Productions et importations au Maroc", [en] P. Trousset (éd.), L'Afrique du Nord antique et médiévale. Productions et exportations africaines. Actualités archéologiques (VIe Colloque international sur l'histoire et l'archéologie de l'Afrique du Nord, Pau, 1993), Paris, 1995, 65-77.

CANFora, L. (1972): Totalità e selezione nella storiografia classica, Bari.

CArcopino, J. (1943): Le Maroc antique, Paris.

Cintas, P. (1948): “Fouilles puniques à Tipasa”, Revue Africaine 92, 263-330.

Desanges, J.

(1978): Recherches sur l'activité des méditerranéens aux confins de l'Afrique. (VIe siècle avant J. C.-IVe siècle après J. C), Roma.

(1980): Pline l'Ancien. H.N. Livre V. 1-46, Paris.

Domínguez Monedero, A. J. (1994): "El periplo del Pseudo-Escílax y el mecanismo comercial y colonial fenicio en época arcaica", [en] Homenaje A. Presedo, Sevilla, 61-80.

Fernández de Castro y Pedrera. R.

(1945): Melilla prehispánica, Madrid.

(1950): "Las necrópolis púnica y romana de Melilla", África 102, 7-11 (=Aldaba 9, 1987, 126-136, Reed.). 
Gozalbes Cravioto. E. (1987): "Economía de la ciudad antigua de Rusadir", Aldaba $5,97-120$.

GreIsSON, Dr. (1973-75): "Sites préhistoriques et gravures rupestres des Aï bou Ichaouen", BAM 9, 103-131.

JoDIN. A.

(1966): "Bijoux et amulettes du Maroc Punique", BAM 6, 65-80.

(1976): "Les grecs d'Asie et l'exploration du litoral marocain", [en] Homenaje García y Bellido, Madrid, vol. II, 75-76.

López Pardo, F. (1996): "Los enclaves fenicios en el África noroccidental: del modelo de las escalas náuticas al de colonización con implicaciones productivas", Gerión 14, 251-288.

Müller, K. (1965): Geographi Graeci Minores, Hildesheim [1855].

Peretti. A.

(1961): "Eforo e Pseudo-Scilace", Studi Classici e Orientali 10, 5-43.

(1988): "Dati stiorici e distanze marine nel Periplo di Scilace", Studi Classici e Orientali 38, 13-137.

Ponsich, M. (1971): Implantation humaine dans le Tangerois. Du paléolithique à la période romaine, Rabat.

RAmón, J. (1995): Las ánforas fenicio-púnicas del Mediterráneo Central y Occidental, Barcelona.

Roget, R. (1924): Le Maroc chez les auteurs anciens, Paris.

SCARDIGLI, B. (1991): I Trattati romano-cartaginesi, Pisa.

Sierra Del Molino, R. (1988): "El Estrecho como línea de demarcación en el comportamiento comercial fenicio: demografía y formas de asentamiento", [en] $I$ CIKG, Madrid, 473-480.

Tarradell Mateu, M.

(1954): "La necrópolis púnico-mauritana del Cerro de San Lorenzo en Melilla", [en] I CAME, Tetuán, 261-266.

(1955): "Avance de la primera campaña de excavaciones en Caf Taht el Gar", Tamuda 3, 307-322.

(1958): "Notas acerca de la primera época de los fenicios en Marruecos", Tamuda 6, 71-80.

(1960): Marruecos púnico, Tetuán.

(1966): "Contribution à 1'Atlas archéologique du Maroc: Región de Totouan", RAM 6, 425-446.

(1967): "El poblamiento antiguo del valle del río Martín", Tamuda 5, 247-274.

THA (1994): Testimonia Hispaniae Antiqua 1, Madrid.

Vuillemot, G. (1965): Reconnaissances aux échelles puniques d'Oranie, Autun. 